\title{
The Blood-Brain Barrier in NeuroAIDS
}

\author{
Wiliam A. Banks ${ }^{*}, 1,2$, Nuran Ercal ${ }^{1,2,3}$ and Tulin Otamis Price ${ }^{4}$
}

${ }^{I}$ Geriatric Research Education and Clinical Center, (GRECC), Veterans Affairs Medical Center-St. Louis, St. Louis, MO, USA; ${ }^{2}$ Division of Geriatrics, Department of Internal Medicine,Saint Louis University School of Medicine, St. Louis, MO, USA; ${ }^{3}$ Department of Chemistry, University of Missouri-Rolla, Rolla, MO, USA; ${ }^{4}$ Department of Biochemistry, Faculty of Pharmacy, Marmara University, Istanbul 81010, Turkey

\begin{abstract}
Nearly every aspect of blood-brain barrier (BBB) function is involved in or affected by HIV-1. The disruption of the BBB tends to be minimal and is not likely the mechanism by which infected immune cells and virus enter the brain. Instead, immune cells, virus and viral proteins likely activate brain endothelial cells and enable their own passage across the BBB by way of highly regulated processes such as diapedesis and adsorptive endocytosis. Viral proteins and cytokines can enter the CNS from the blood and provide a mechanism by which HIV-1 can affect CNS function independent of viral transport. Brain endothelial cells can also secrete neuroimmunoactive substances when stimulated by HIV-1, gp120, and Tat. Efflux systems such as p-glycoprotein transport anti-virals in the brain-to-blood direction, thus hampering effective accumulation of drug by the CNS. Overall, the BBB plays a major role in establishing and maintaining virus within the CNS and neuroAIDS.
\end{abstract}

Keywords: Blood-brain barrier, transporter, virus, HIV-1, AIDS, cytokine.

\section{INTRODUCTION}

The blood-brain barrier (BBB) is more than just a barrier which separates the central nervous system (CNS) from the blood. It is also a regulatory interface through which nutrients, xenobiotics, cytokines, immune cells, and viruses pass into and out of the CNS [6]. All of these processes are themselves controlled or affected by events in the CNS and periphery. The BBB has secretory functions as well, being able to produce and secrete neuroactive and immunoactive substances. These diverse functions mean that not only can the BBB be a target of disease, it can also be a source of disease and so is itself a therapeutic target.

Almost every aspect of the BBB is involved in neuroAIDS. For example: HIV-1 crosses the BBB inside infected immune cells and as free virus through intricate processes, not by simple leakage across a disrupted BBB; Viral proteins, including gp120 and Tat, can directly cross the BBB where they may exert direct effects on the CNS; Cytokines in the blood are transported across the BBB in significant amounts by specific, saturable transport systems and cytokines produced by CNS tissues and secreted into CSF can enter the blood as the CSF is reabsorbed; Retroviral drugs achieve subtherapeutic levels in the CNS because of saturable efflux systems located at the BBB; HIV-1 and viral products produced in the CNS can also find their way back into the periphery where they may be able to reinfect peripheral tissues. Additionally, the BBB itself undergoes pathological changes and oxidative stress when exposed to virus and viral proteins. These changes may lead eventually to a disruption of the $\mathrm{BBB}$, but more immediately induce the cells comprising the BBB to release neuroactive and neuroimmune products.

*Address correspondence to this author at the VAMC, 915 N. Grand Blvd, St. Louis, MO 63106, USA; Tel: (314) 289-7084; Fax: (314) 289 6374; E-mail: bankswa@slu.edu
A picture emerges of a BBB that is greatly impacted by HIV-1. Many of the alterations in the BBB do not require productive infection or even whole virus but can be induced by gp120 and Tat. Interestingly, the BBB is minimally disrupted in neuroAIDS [86]. In contrast to a relatively intact $\mathrm{BBB}$, almost every other aspect of BBB function is affected in ways that likely encourage and sustain the neuroAIDS phenomena. Here, we first review normal functions of the BBB that are relevant to an understanding of neuroAIDS. We then review some of the major ways in which the BBB is involved in neuroAIDS.

\section{ESSENTIALS OF THE BBB}

\section{The Barrier}

Evidence for the BBB can be traced back to experiments conducted in Paul Erlich's laboratory in the 1880's [25]. The essential observations were with dyes which could stain the brain when injected into the CNS but not when injected into the blood. These observations eventually gave way to the idea that some barrier must be preventing the dye from entering the CNS from the blood. The nature of that barrier, however, and even whether there was actually a physical barrier was hotly contested for decades. Seminal observations by Hugh Davson and others argued that a barrier must exist and that its location in adult mammals was most likely at the level of brain endothelium [25]. Evidence for parallel barriers at the choroid plexus and at the circumventricular organs also accumulated [49,55].

The capillary bed of the brain does not look unique whether examined grossly or at the light microscopy level and so theories competing with that of a vascular barrier were advanced. It wasn't until Karnovsky and colleagues examined the capillary bed of the brain with electron microscopy in the late 1960's that a modern view of the BBB emerged [89]. They showed that the capillary bed of the brain had several modifications that prevented the produc- 
tion of a plasma ultrafiltrate typical of most capillary tissue beds. Chief among these modifications was the presence of tight junctions, structures which essentially fused together membranes of adjacent endothelial cells. This eliminated all interendothelial gaps. A lack of fenestrations and a low rate of pinocytosis were also found to limit leakage through individual endothelial cells. Hence, a circulating substance is presented with what is essentially a continuous cell membrane.

\section{Mechanisms of Entry}

Because the dyes used to examine BBB integrity bind tightly to albumin, they assess permeability to large proteins. However, the element lanthanum has been extensively used in electron microscopy studies to show that even substances of extremely low molecular weight are also prevented from leaking across the BBB. This essentially total block of leakage denies the brain the ultrafiltrate derived from plasma by which other tissues are nourished. These and many other needs of the brain are still met by the vascular bed, but by very different mechanisms. Chief among these are membrane diffusion and saturable transport.

Membrane diffusion involves the substance melding into the luminal (blood) side of the plasma membrane of the capillary wall and exiting from the abluminal (brain) side [74]. Most substances likely partition from the luminal membrane into the endothelial cytoplasm, from the cytoplasm to the abluminal membrane, and finally, from the abluminal membrane into the brain interstitial fluid. However, another pathway has been proposed for both endothelial and epithelial barriers: that of remaining in the membrane and diffusing throughout the cell membrane. This pathway relies on the observation that the luminal and abluminal membranes are actually continuous and are only separated by the presence of tight junctions. Tight junctions serve two functions: as gates and as fences. By occluding and obliterating intercellular spaces, tight junctions block paracellular passage and so act as gates between the blood and brain sides of the BBB. Tight junctions also divide the cell membrane and so define its luminal and abluminal sectors. The luminal and abluminal membranes are distinct in their protein and lipid compositions $[62,105]$ and it is the fence-like function of the tight junctions which prevents the two membranes from mixing [27]. However, tight junctions may not completely occlude the inner leaflets as the inner leaflets of the luminal and abluminal membranes are similar. Thus, substances may be able to diffuse easily between inner leaflets of the luminal and abluminal membranes.

Substances which can most readily cross the BBB by way of membrane diffusion are small and lipid soluble [20,31]. However, substances which are too lipid soluble are unable to diffuse from the membranes back into the endothelial cytoplasm or brain interstitial fluid. Therefore, the ideal substances for this pathway retain some solubility in aqueous solutions. Molecular weight is a penalty against diffusion by this mechanism, but no absolute level is known. The oft stated cut-off of 400-600 Daltons is a misinterpretation of the data of Levin. Many xenobiotics and some peptides larger than 600 Daltons enter the CNS by way of membrane diffusion $[12,34,46,74,108]$. The largest substance shown to enter the brain by way of membrane diffusion is the cytokine CINC1 with a molecular weight of about 7800 [79].

Saturable transporters are key to providing the CNS with all of its requirements [36]. Glucose, amino acids, free fatty acids, minerals, vitamins, electrolytes, peptides, and regulatory proteins are examples of substances transported across the BBB. Because these transporters adapt to the metabolic demands of the brain, the BBBs of developing, mature, and senescent brains have many important differences [35]. It is increasingly clear that disease also adapts or maladapts the BBB and that some of the influences on the BBB arise from peripheral tissues rather than the CNS $[7,54,78,80,116]$. Saturable transporters can be classified [112] as those requiring energy (active transporters) and those not requiring energy (facilitated diffusion). Many of the saturable transporters of the BBB, including Glut-1 which transports glucose across the BBB, are facilitated diffusion systems [36]. Another subset of saturable transport is that of receptormediated transcytosis. The term transcytosis designates the involvement of vesicles and the requirement for energy in the transport process. Extremely large substances and viruses clearly use vesicular-dependent mechanisms to cross the $\mathrm{BBB}$, whereas smaller substances such as ions or glucose use pore transporters. It is unclear, however, at what molecular weight vesicles are required. Some peptides less than 1000 $\mathrm{Da}$ are known to use vesicular pathways [94,100], whereas some larger substances do not [14]. The cytokine interleukin-2, molecular weight of about $12 \mathrm{kDa}$, has been suggested to be a ligand for the BBB efflux transporter p-glycoprotein (P-gp) [39], a very specialized pore transporter [21].

Adsorptive endocytosis is a mechanism by which glycoproteins can cross the BBB [104]. It depends on the lectinlike interactions between the glycoprotein of interest and other glycoproteins on the surface of the brain endothelial cell $[105,114]$. Such glycoproteins are not specific but are selective so that a glycoprotein will only interact with specific sugars presented in certain confirmations. These sugars and their attached proteins are often distributed in a polarized fashion; that is, their distribution is not homogeneous on the luminal $v s$ abluminal surfaces [105]. This means that transport by the mechanism of adsorptive endocytosis is often directional; that is, it is only in the blood-to-brain or brainto-blood direction $[26,104]$. For example, the glycoprotein wheatgerm agglutinin binds to sialic acid. Most of the BBB proteins containing sialic acid are on the luminal surface of the BBB. Therefore, wheatgerm agglutinin injected into the blood binds to the luminal surface of brain endothelial cells, is internalized in vesicles which are exocytosed to the abluminal surface, and so enters the brain interstitial fluid [9]. Wheatgerm agglutinin does not bind to the abluminal surface after injection into the CNS and so is not transcytosed across brain endothelial cells.

The kinetics of transport by adsorptive endocytosis differ in important ways from saturable transport, even when the cell surface glycoprotein is a transporter protein. Because a cell surface sugar can be ubiquitous, it is often difficult to demonstrate classical saturation kinetics for adsorptive endocytosis. In fact, it may take a critical mass of binding to induce adsorptive endocytosis so that excess material may paradoxically increase, rather than inhibit, transport. For the $\mathrm{BBB}$, adsorptive endocytosis may in some cases be a reac- 
tion to the toxic event of binding to glycoproteins on the brain endothelial cell surface. Viruses use adsorptive endocytosis to enter cells, including brain endothelial cells $[32,66,93,113]$. One of the best examples is binding of influenza virus to sialic acid on cell surface glycoproteins.

Diapedesis, the process by which immune cells cross the BBB, has similarities to adsorptive endocytosis [64]. Glycoproteins on the immune cell bind to glycoproteins on the brain endothelial cell [43]. This initiates a series of events involving cytokines and other messengers in a paracrine-like communication between the immune and endothelial cells. Although it is often assumed that immune cells cross an already disrupted $\mathrm{BBB}$, the best evidence shows that immune cells use diapedesis to tunnel through, not between, brain endothelial cells and can do so at healthy sections of the BBB $[42,47,109]$.

\section{Mechanisms of Exit}

The BBB is a bidirectional barrier, transporting substances in the brain-to-blood direction as well as the bloodto-brain direction. The BBB is also a polarized barrier; that is, some substances are transported only (or primarily) in either one direction or the other. Efflux, or brain-to-blood transport, is as important to the normal functioning of the $\mathrm{CNS}$ as is influx, or blood-to-brain transport. Some of these efflux systems, such as the P-gp system, transport many different kinds of xenobiotics out of the CNS [21].

Many of the considerations outlined above for blood-tobrain influx systems apply to the efflux systems. In fact, facilitated diffusion systems are actually bidirectional with the direction of flux being from the high to the low concentration.

Any substance in CSF will exit the CNS as the CSF is absorbed [98]. Two major routes for CSF reabsorption have been identified. The first is at the arachnoid villi and the second is by way of nasal drainage $[23,111]$. The latter pathway leads directly to the cervical lymph nodes. Substances exiting by this route have the potential to alter the immunologic response of the body to them [58] or can achieve substantial levels in blood $[29,33,65]$.

\section{Other Roles of the BBB}

Besides roles in transport, the BBB has other functions as well. The choroid plexus, the brain endothelial cells, and the cells delimiting the circumventricular organs all have secretory capacity. Brain endothelial cells, which are the best studied in this regard, can secret prostaglandins, nitric oxide, cytokines, and other substances $[37,38,53,61,69,90,103]$. This secretory capacity can be altered as exemplified by stimulation of cytokine release by lipopolysaccharide.

\section{THE BBB IN NEUROAIDS}

Each of the features of the BBB discussed above is involved or affected in neuroAIDS. Below, examples of how the BBB is affected are discussed.

\section{BBB Disruption}

The degree to which the BBB is disrupted is often characteristic for a neurological disease and ranges among them from minimal to massive. The BBB disruption in neuroAIDS is generally categorized as a minimal or low grade disruption $[41,50,86]$. It seems often misconstrued in the literature that first the BBB is disrupted and then virus, proteins, and immune cells leak into the brain. More likely, the virus and viral proteins activate immune and brain endothelial cells and so facilitates the regulated processes, including diapedesis and adsorptive endocytosis, by which virus and immune cells enter the brain. With diapedesis and some types of vesicular trafficking, serum proteins are carried along into the brain $[42,63,106,109]$. This is because when a vesicle or immune cell transfers through a brain endothelial cell, some plasma is trapped in the vesicles or tubules that allow its passage [85].

In vitro evidence suggests that paracellular transport may also be increased when monolayers of brain endothelial cells are exposed to HIV-1 or viral proteins. However, many studies have not really determined whether the increased permeability is mediated by transcytotic or paracellular pathways. In vivo, almost all CNS injuries, even traumatic ones, increase $\mathrm{BBB}$ disruption through transcytotic mechanisms $[26,63,68]$ and most viruses and immune cells crossing the BBB use transcytotic mechanisms $[32,42,109]$. Nevertheless, some tight junction proteins are reduced with in vitro exposure of brain endothelial cells to virus and viral proteins $[3,24,56]$. For example, the ZO-1 and ZO-2 proteins are altered whereas occludin is not [56]. Occludin is one of the cell-cell adhesion molecules, whereas ZO-1 links the adhesion molecules to the actin cytoskeleton [27]. Decreased ZO1 might, therefore, be involved in the cytoskeletal rearrangement necessary for transcytosis as well as for increased paracellular permeability.

\section{Virus and Virus Protein Passage Across the BBB}

HIV-1 crosses the BBB both within infected immune cells and as a free virus $[11,59,70,73,84]$. Immune cells cross the $\mathrm{BBB}$ on a regular basis, probably as part of an immune surveillance of the CNS. The review in this issue by Gendelman [44] more fully describes the mechanisms by which immune cells can cross the BBB. Such passage may account, in part, for the apparent minimal "disruption" of the BBB [5]. As each immune cell crosses by diapedesis, some plasma protein will accompany it. Thus, an increase in immune cell entry into the CNS could elevate the level of plasma proteins in the CSF.

HIV-1 as a free virus can also cross the BBB [11]. Such passage is dependent on a viral expression of gp120 and involves several regulated stages of initial binding and internalization [8]. Much of the virus taken up by brain endothelial cells fuses after internalization and so, presumably, is not available for passage into the CNS [11,18]. Additionally, the majority of a virus taken up by brain endothelial cells in vitro is recycled back to the blood rather than the CNS, some after degradation [72]. Nevertheless, some amount of the virus is ultimately transcytosed completely across the brain endothelial cells and into the CNS compartment. Interestingly, uptake and transport of free virus and viral proteins are not species dependent. Mouse brain endothelial cells take up free virus and viral proteins as readily as human brain endothelial cells [15].

Both gp120 and Tat readily cross the BBB [13,17]. Adsorptive endocytosis likely mediates gp120 transport; that is, 
it participates as a glycoprotein in a lectin-like reaction with glycoproteins on the brain endothelial cell surface. Free virus transport is dependent on gp120 for binding and internalization $[11,18]$. Passage of gp120 can be greatly enhanced by the glycoprotein wheatgerm agglutinin, as can the transport of free HIV-1 virus [13]. This and studies with protamine sulfate and heparin demonstrate roles in uptake and passage for cell surface proteins containing sialic acid and involving the heparan sulfate proteoglycans, or sydnecans [18]. Syndecans are abundantly expressed on brain endothelial cells and can facilitate the uptake of HIV [22]. The adult BBB also expresses chemokine receptors other than CD4 which in other tissues act as co-receptors for binding HIV-1 [71]. It may be that the syndecans and chemokine receptors interact at the BBB as they do on other tissues $[51,95]$ and so could be the binding and transport proteins of the BBB for HIV-1.

These multiple mechanisms by which infected immune cells, free virus, and viral proteins can enter the CNS have implications for the development of neuroAIDS. It is well known that neuroAIDS is not mediated through the direct infection of neurons by HIV-1. These pathways provide a mechanism by which events in the serum can have a direct effect on brain function, as well as account for the pathways by which virus and activated immune cells enter the CNS.

\section{Cytokine Transport}

Several proinflammatory cytokines are transported across the BBB by unique saturable transport systems. Interleukin$1 \forall,-1 \beta$, and receptor antagonist are transported by either the same transporter or a family of transporters with overlapping affinities [16]. Interleukin-6, tumor necrosis factor $-\forall$, brainderived neurotrophic factor, some of the nerve growth factors and interferons, transforming growth factor, ciliary neurotrophic factor, and several other cytokines have their own transporters as well [75-77,81,82]. Transport of these cytokines across the BBB has been shown to affect brain functions [10].

Proinflammatory cytokine levels are elevated in the blood of patients with AIDS [2,52]. Therefore, it is likely that these elevated blood levels are one of the mechanisms that produce elevated brain levels of cytokines.

Saturable transport in the brain-to-blood direction has been shown to only occur for interleukin-2 [83]. However, cytokines can enter the circulation from the CNS with the reabsorption of cerebrospinal fluid. Because of favorable pharmacokinetics (a relatively long half-life in serum and a small volume of distribution in blood) of cytokines, the CNS can make substantial contributions to the serum levels $[29,30]$. Therefore, the increased cytokine production within the CNS, induced in neuroAIDS, may contribute to enhanced serum levels as well.

\section{Endothelial Cell Secretions}

The brain endothelial cell has itself emerged as a secretory tissue. Furthermore, these secretions are clearly involved in pathophysiology. For example, the increase in body temperature in response to lipopolysaccharide is mediated by release of prostaglandins from the brain microvasculature. The unique polarization of the BBB is probably especially relevant to diseases such as AIDS. Polarization likely occurs in two distinct ways: 1) the BBB can receive stimula- tion from either substances in the blood or in the brain interstitial fluid; 2) the BBB can secret substances into either the blood stream or into the CNS.

Both Tat and gp120 have been shown to stimulate the release of cytokines from the BBB $[53,88,115]$. HIV-1 and gp120, but not nonglycosylated gp120, can induce the BBB to express and release the cytokine endothelin-1 [37] which, in turn, induces release of nitric oxide. Thus, circulating virus and viral proteins have the ability to increase brain levels of cytokines, prostaglandins, and nitric oxide without themselves entering the brain.

\section{Efflux of Antiretrovirals}

The p-glycoprotein (P-gp) efflux pump is a member of the $\mathrm{ABC}$ family of transporters [21]. It is inserted between the inner and outer leaflets of the luminal membrane of the brain endothelial cells which comprise the BBB. Its ligands include a vast number of xenobiotics seemingly unrelated one another, such as digoxin, vincristine, cyclosporin, verapamil, ivermectin, morphine, endogenous peptides, and dilantin $[19,40,91,92]$. Depending on the affinity of P-gp for the ligand, this efflux system can prevent accumulation in the brain to the extent that the ligand does not exert a CNS effect. Every one of the HIV protease inhibitors is a ligand for P-gp $[45,60]$. As such, their accumulation in the brain is poor, being $3-14 \%$ of what it would be in the absence of $\mathrm{P}$ gp [57]. As such, the P-gp system is the main reason why protease inhibitors seldom reach therapeutic levels in the CNS.

Other transporters efflux other anti-viral drugs $[48,101,107]$. Best characterized in this regard is zidovudine which is the ligand for probenecid-sensitive organic anion carriers $[67,96,99,110]$.

\section{Efflux of Virus and Viral Proteins}

One reason that neuroAIDS is of such concern is that HIV-1 in the brain is sheltered from circulating anti-viral agents. As such, the CNS may act as a reservoir of virus for reinfection of the body. However, few studies have concerned themselves with how immune cells or viruses exit the CNS. One study determined whether gp120 injected into the lateral ventricles of the brain could reenter the peripheral tissues [28]. That study found that gp120 exited the CNS primarily with the reabsorption of the CNS via the nasal lymphatics. If a virus were to also take this route, it would mean that it can enter the lymph nodes without entering the blood and being exposed to circulating antivirals. The lymph nodes are an early site of HIV-1 replication after infection and before the onset of AIDS. Thus, a brain to lymphatic node route would provide a relatively sheltered mechanism by which HIV-1 could reinfect the periphery.

\section{Viral Proteins and Oxidative Stress in Brain Endothelial Cells}

Under physiological conditions, the integrity of the BBB is protected from oxidative stress (i.e., a state of increased free radical formation and its effects on cellular constituents) because the brain endothelial cells have high intracellular levels of antioxidants such as glutathione (GSH), superoxide dismutase (SOD), catalase (CAT), and glutathione peroxi- 


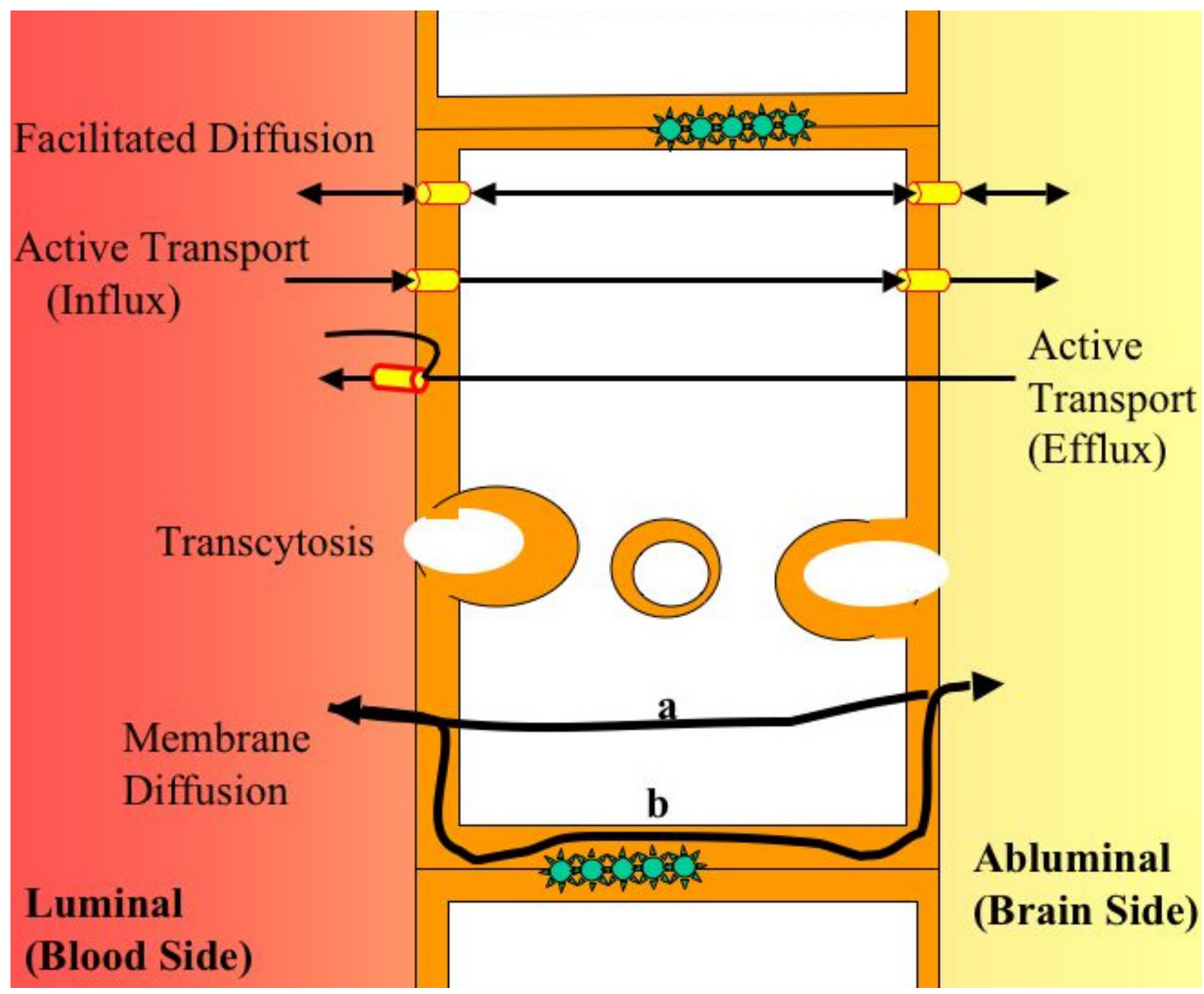

Fig. (1). Categorization of the Mechanisms of Passage Across Brain Endothelial Cells. Saturable systems can be energy-independent (facilitated diffusion) or energy-requiring (active transport). Facilitated diffusion transfers a substance from the compartment of a higher concentration to the compartment of a lower concentration and is, therefore, bidirectional. Active transport is usually unidirectional and can be directed in either the blood-to-brain (influx) or the brain-to-blood (efflux) direction. The saturable transporters can be located on the luminal or abluminal membranes or both. P-gp exemplifies an efflux system located predominately in the luminal membrane which can bind to before they enter the cell cytoplasm. Transcytosis is vesicular and energy dependent. It can range from highly specific systems (a subset of active transport) to reactions probably designed to cleanse the membrane of toxic glycoproteins sticking to the membranes. Viruses use transcytotic mechanisms to invade the CNS and diapedesis likely uses much of the transcytotic machinery. Membrane diffusion is nonsaturable; small, lipid soluble molecules cross by this mechanism. Two pathways have been proposed for membrane diffusion: through endothelial cytoplasm (a) and through the inner leaflet behind tight junctions (b).

dase (GPx). They protect cells from peroxidative damage. On the other hand, the BBB cells are innately loaded with easily peroxidizable polyunsatured fatty acids; this makes the BBB more vulnerable to oxidative damage and to lipid peroxidation in particular [97].

Free radical production and the resulting oxidative stress, combined with activation of inflammatory processes, play a key role in the pathogenesis of neuroAIDS. A recent review discusses the mechanisms of damage to brain microvascular endothelial cells and alterations of the BBB's integrity by oxidative stress in HIV infection [102]. Both gp120 and Tat cause free radical production and oxidative stress. A study of the HIV-1 Tat protein demonstrated that exposure of endothelial cells to the HIV-1 Tat protein resulted in a dosedependent decrease in intracellular GSH [4]. It was shown that cerebral glutathione also plays an important role in the maintenance of membrane integrity and the proper functioning of BBB [1]. Our research demonstrated that oxidative stress was induced in vitro in an immortalized cell line of rat brain endothelial cells, RBE4 cells (as an in vitro BBB model), when exposed to the HIV-1 proteins gp120 and Tat. The HIV-1 proteins depleted intracellular GSH, increased lipid peroxidation, and reduced antioxidant enzyme levels (catalase, glutathione peroxidase, and glutathione reductase). Therefore, our results indicate that RBE4 cells were oxidatively challenged by HIV proteins [87].

In this context, increased cellular oxidative stress can be, in part, responsible for the major mechanism causing possible HIV-1 protein-induced disruption or alteration in transport systems of the BBB in neuroAIDS patients. 


\section{CONCLUSIONS}

Many aspects of the BBB are involved in neuroAIDS. Surprisingly, disruption of the BBB is minimal, but many of the more sophisticated aspects of BBB function are recruited by HIV-1. Free virus and infected immune cells cross the BBB by the mechanisms of transcytosis and diapedesis. Unlike many viruses, HIV-1 would probably be neurotoxic, even if the virus did not invade the brain. This is because substantial amounts of gp120 and Tat, viral proteins which themselves are highly neurotoxic, can cross the BBB in substantial amounts. Additionally, cytokines, many of which are elevated in the blood of patients with HIV-1, can cross the BBB to directly exert effects on the CNS. The brain endothelial cells are another source of potential neurotoxins. They normally secrete cytokines, nitric oxide, prostaglandins, and other substances and the secretion of some of these substances is known to be enhanced by HIV-1, gp120, and proinflammatory events.

\section{REFERENCES}

[1] Agrawal R, Shukla GS. (1999). Potential role of cerebral glutathione in the maintenance of blood-brain barrier integrity in rat. Neurochemical Research. 24:1507-1514.

[2] Alonso K, Pontiggia P, Medenica R, Rizzo R. (1997). Cytokine patterns in adults with AIDS. Immunological Investigation. 26:341350.

[3] Andras IE, Pu H, Deli MA, Nath A, Hennig B, Toborek M. (2003). HIV-1 Tat protein alters tight junction protein expression and distribution in cultured brain endothelial cells. Journal of Neuroscience Research. 74:255-265.

[4] Antonawich FJ, Azmitia EC, Kramer HK, Strand FL. (1994). Specificity versus redundancy of melanocortins in nerve regeneration. In: Strand FL, Beckwith B, Chronwall B, Sandman CA (eds) Models of Neuropeptide Action. New York Academy of Sciences, New York, pp 60-73.

[5] Avison MJ, Nath A, Greene-Avison R, Schmitt FA, Bales RA, Ethisham A, Greenberg RN, Berger JR. (2004). Inflammatory changes and breakdown of microvascular integrity in early human immunodeficiency virus dementia. Journal of Neurovirology 10:223-232.

[6] Banks WA. (1999). Physiology and pathology of the blood-brain barrier: implications for microbial pathogenesis, drug delivery and neurodegenerative disorders. Journal of Neurovirology 5:538-555.

[7] Banks WA.. (2003). Is obesity a disease of the blood-brain barrier? Physiological, pathological, and evolutionary considerations. Current Pharmaceutical Design 9:801-809

[8] Banks WA, Akerstrom V, Kastin AJ. (1998). Adsorptive endocytosis mediates the passage of HIV-1 across the blood-brain barrier: evidence for a post-internalization coreceptor. Journal of Cell Science. 111:533-540.

[9] Banks WA, Broadwell RD. (1994). Blood to brain and brain to blood passage of native horseradish peroxidase, wheat germ agglutinin and albumin: pharmacokinetic and morphological assessments. Journal of Neurochemistry. 62:2404-2419.

[10] Banks WA, Farr SA, La Scola ME, Morley JE. (2001). Intravenous human interleukin- $1 \alpha$ impairs memory processing in mice: Dependence on blood-brain barrier transport into posterior division of the septum. Journal of Pharmacology and Experimental Therapeutics. 299:536-541.

[11] Banks WA, Freed EO, Wolf KM, Robinson SM, Franko M, Kumar VB . (2001). Transport of human immunodeficiency virus type 1 pseudoviruses across the blood-brain barrier: role of envelope proteins and adsorptive endocytosis. Journal of Virology. 75:46814691.

[12] Banks WA, Kastin AJ. (1985). Peptides and the blood-brain barrier: lipophilicity as a predictor of permeability. Brain Research Bulletin. 15:287-292.

[13] Banks WA, Kastin AJ. (1998). Characterization of lectin-mediated brain uptake of HIV-1 gp120. Journal of Neuroscience Research. 54:522-529.
[14] Banks WA, Kastin AJ, Fischman AJ, Coy DH, Strauss SL. (1986) Carrier-mediated transport of enkephalins and N-Tyr-MIF-1 across blood-brain barrier. American Journal of Physiology. 251:E477E482.

[15] Banks WA, Kumar VB, Franko MW, Bess JW, Jr., Arthur LO. (2005). Evidence that the species barrier of human immunodeficiency virus-1 does not extend to uptake by the blood-brain barrier: Comparison of mouse and human brain microvessels. Life Science. 77:2361-2368.

[16] Banks WA, Ortiz L, Plotkin SR, Kastin AJ. (1991). Human interleukin . (IL). $1 \alpha$, murine IL- $1 \alpha$ and murine IL-1 $\beta$ are transported from blood to brain in the mouse by a shared saturable mechanism. Journal of Pharmacology and Experimental Therapeutics. 259:988996.

[17] Banks WA, Robinson SM, Nath A. (2005). Permeability of the blood-brain barrier to HIV-1 Tat. Experimental Neurology. 193:218-227.

[18] Banks WA, Robinson SM, Wolf KM, Bess JW, Jr., Arthur LO. (2004). Binding, internalization, and membrane incorporation of human immunodeficiency virus-1 at the blood-brain barrier is differentially regulated. Neuroscience. 128:143-153.

[19] Begley DJ. (1992). The interaction of some centrally active drugs with the blood-brain barrier and circumventricular organs. Progress in Brain Research. 91:163-169.

[20] Begley DJ. (1994). Strategies for delivery of peptide drugs to the central nervous system: exploiting molecular structure. Journal of Controlled Release 29:293-306.

[21] Begley DJ. (2004). ABC transporters and the blood-brain barrier. Current Pharmaceutical Design. 10:1295-1312.

[22] Bobardt MD, Salmon P, Wang L, Esko JD, Gabuzda D, Fiala M, Trono D, Van der Schueren B, David G, Gallay PA. (2004). Contribution of proteoglycans to human immunodeficiency virus type 1 brain invasion. Journal of Virology. 78:6567-6584.

[23] Boulton M, Flessner M, Armstrong D, Mohamed R, Hay J, Johnston M. (1999). Contribution of extracranial lymphatics and arachnoid villi to the clearance of a CSF tracer in the rat. American Journal of Physiology. 276:R818-R823.

[24] Boven LA, Middel J, Verhoef J, De Groot CJ, Nottet HS. (2000). Monocytes infiltration is highly associated with loss of tight junction protein zonula occludens in HIV-1-associated dementia. Neuropathology and Applied Neurobiology 26:356-362.

[25] Bradbury M. (1979). The Concept of a Blood-Brain Barrier. John Wiley and Sons Ltd, New York.

[26] Broadwell RD . (1989). Transcytosis of macromolecules through the blood-brain barrier: a cell biological perspective and critical appraisal. Acta Neuropathologica . (Berl). 79:117-128.

[27] Brown RC, Davis TP. (2002). Calcium modulation of adherens tight junction function: a potential mechanism for blood-brain barrier disruption after stroke. Stroke. 33:1706-1711.

[28] Cashion MF, Banks WA, Bost KL, Kastin AJ. (1999). Transmission routes of HIV-1 gp120 from brain to lymphoid tissues. Brain Research. 822:26-33.

[29] Chen G, Castro WL, Chow HH, Reichlin S. (1997). Clearance of ${ }^{125}$ I-labelled interleukin-6 from brain into blood following intracerebroventricular injection in rats. Endocrinology. 138:4830-4836.

[30] Chen G, Reichlin S. (1998). Clearance of $\left[{ }^{125} \mathrm{I}\right]$-tumor necrosis factor- $\alpha$ from the brain into the blood after intracerebroventricular injection into rats. Neuroimmunomodulation 5:261-269.

[31] Chikhale EG, Ng KY, Burton PS, Borchardt RT. (1994). Hydrogen bonding potential as a determinant of the in vitro and in situ bloodbrain barrier permeability of peptides. Pharmcological Research. 11:412-419.

[32] Chou S, Dix RD. (1989). Viral infections and the blood-brain barrier. In: Neuwelt EA . (ed). Implications of the Blood-Brain Barrier and Its Manipulation, Volume 2: Clinical Aspects. Plenum Publishing Corporation, New York, pp 449-468.

[33] Clark RG, Jones PM, Robinson ICAF. (1983). Clearance of vasopressin from cerebrospinal fluid to blood in chronically cannulated Brattleboro rats. Neuroendocrinology. 37:242-247.

[34] Cornford EM, Braun LD, Oldendorf WH, Hill MA . (1982). Comparison of lipid-mediated blood-brain-barrier penetrability in neonates and adults. American Journal of Physiology. 243:C161-C168

[35] Davson H, Segal MB. (1996). Ontogenetic aspects of the cerebrospinal system. Physiology of the CSF and blood-brain barriers. CRC Press, Inc, Boca Raton, pp 607-662. 
[36] Davson H, Segal MB. (1996). Special aspects of the blood-brain barrier. Physiology of the CSF and Blood-Brain Barriers. CRC Press, Boca Raton, pp 303-485.

[37] Didier N, Banks WA, Creminon C, Dereuddre-Bosquet N, Mabondzo A. (2002). Endothelin-1 production at the in-vitro bloodbrain barrier during HIV infection. Neuroreport. 13:1179-1183.

[38] Dorheim MA, Tracey WR, Pollock JS, Grammas P. (1994). Nitric oxide synthase activity is elevated in brain microvessels in Alzheimer's disease. Biochemistry and Biophysics Research Communications. 205:659-665

[39] Drach J, Gsur A, Hamilton G, Zhao S, Angerler J, Fiegl M, Zojer N, Raderer M, Haberl I, Andreeff M, Huber H. (1996). Involvement of P-glycoprotein in the transmembrane transport of interleukin-2 . (IL-2)., IL-4, and interferon-gamma in normal human T lymphocytes. Blood. 88:1747-1754.

[40] Elferink RPJO, Zadina JE. (2001). MDR1 P-glycoprotein transports endogenous opioid peptides. Peptides. 22:2015-2020.

[41] Elovaara I, Iivanainen M, Valle SL, Suni J, Tervo T, Lahdevirta J . (1987). CSF protein and cellular profiles in various stages of HIV infection related to neurological manifestations. Journal of Neurological Science. 78:331-342.

[42] Engelhardt B, Wolburg H. (2004). Minireview: Transendothelial migration of leukocytes: through the front door or around the side of the house? European Journal of Pharmacology. 34:2955-2963.

[43] Etienne-Manneville S, Manneville JB, Adamson P, Wilbourn B, Greenwood J, Couraud PO. (2000). ICAM-1-coupled cytoskeletal rearrangements and transendothelial lymphocyte migration involve intracellular calcium signaling in brain endothelial cell lines. Journal of Immunology. 165:3375-3383.

[44] Gendelman HE. (2006). Human Immunodeficiency virusmononuclear phagocyte interactions: Emerging avenues of biomarker discovery, modes of viral persistence and disease pathogenesis. Current HIV Research 4:in press.

[45] Glynn SL, Yazdanian M. (1998). In vitro blood-brain barrier permeability of nevirapine compared to other HIV antiretroviral agents. Journal of Pharmcological Science. 87:306-310.

[46] Gray RA, Vander Velde DG, Burke CJ, Manning MC, Middaugh CR, Borchardt RT. (1994). Delta-sleep-inducing peptide: solution conformational studies of a membrane-permeable peptide. Biochemistry. 33:1323-1331.

[47] Greenwood J, Bamforth S, Wang Y, Devine . (1995). The bloodretinal barrier in immune-mediated diseases of the retina. In: Greenwood J, Begley DJ, Segal MB . (eds). New Concepts of a Blood-Brain Barrier. Plenum Press, New York, pp 315-326.

[48] Groothuis DR, Levy RM. (1997). The entry of antiviral and antiretrovial drugs into the central nervous system. Journal of Neurovirology. 3:387-400.

[49] Gross PM, Weindl A. (1987). Peering through the windows of the brain. Journal of Cerebral Blood Flow and Metabolism. 7:663-672.

[50] Hall CD, Snyder CR, Robertson KR, Messenheimer JA, Wilkins JW, Robertson WT, Whaley RA, Van der Horst C, Silverman LM. (1992). Cerebrospinal fluid analysis in human immunodeficiency virus infection. Annals of Clinical Laboratory Science. 22:139-143.

[51] Hamon M, Mbemba E, Charnaux N, Slimani H, Brule S, Saffar L, Vassy R, Prost C, Lievre N, Starzec A, Gattegno L. (2004). A syndecan-4/CXCR4 complex expressed on human primary lymphocytes and macrophages and HeLa cell line binds the CXC chemokine stromal cell-derived factor-1 . (SDF-1).. Glycobiology. 14:311-323.

[52] Hittinger G, Poggi C, Delbeke E, Profizi N, Lafeuillada A. (1998). Correlation between plasma levels of cytokines and HIV-1 RNA copy number in HIV-infected patients. Infection. 26:100-103

[53] Hofman F, Chen P, Incardona F, Zidovetzki R, Hinton DR. (1999). HIV-tat protein induces the production of interleukin- 8 by human brain-derived endothelial cells. Journal of Neuroimmunology. 94:28-39.

[54] Horani MH, Mooradian AD. (2003). The effect of diabetes on the blood brain barrier. Current Pharmaceutical Design. 9:833-840.

[55] Johanson CE. (1988). The choroid plexus-arachnoid membranecerebrospinal fluid system. In: Boulton AA, Baker GB, Walz W . (eds). Neuromethods; The Neuronal Microenvironment. The $\mathrm{Hu}-$ mana Press, Clifton, New Jersey, pp 33-104.

[56] Kanmogne GD, Primeaux C, Grammas P. (2005). HIV-1 gp120 proteins alter tight junction protein expression and brain endothelial cell permability: implications for the pathogenesis of HIV- associated dementia. Journal of Neuropathology and Experimental Neurology. 64:498-505.

[57] Kim RB, Fromm MF, Wandel C, Leake B, Wood AJJ, Roden DM, Wilkinson GR. (1998). The drug transporter p-glycoprotein limits oral absorption and brain entry of HIV-1 protease inhibitors. Journal of Clinical Investigation. 101:289-294.

[58] Knopf PM, Cserr HF, Nolan SC, Wu TY, Harling-Berg CJ. (1995) Physiology and immunology of lymphatic drainage of interstitial and cerebrospinal fluid from the brain. Neuropathology and Applied Neurobiology 21:175-180.

[59] Koyanagi Y, Tanaka Y, Kira J, Ito M, Hioki K, Misawa N, Kawano Y, Yamasaki K, Tanaka R, Suzuki Y, Ueyama Y, Terada E, Tanaka T, Myasaka M, Kobayashi T, Kumazawa Y, Yamamoto N. (1997). Primary human immunodeficiency virus type 1 viremia and central nervous system invasion in a novel hu-PBLimmunodeficient mouse strain. Journal of Virology. 71:2417-2424.

[60] Lee CGL, Gottesman MM, Cardarelli CO, Ramachandra M, Jeang KT, Ambudkar SV, Pastan I, Dey S. (1998). HIV-1 protease inhibitors are substrates for the MDR1 multidrug transporter. Biochemistry. 37:3594-3601.

[61] Lee YW, Hennig B, Fiala M, Kim KS, Toborek M. (2001). Cocaine activates redox-regulated transcription factors and induces TNF-alpha expression in human brain endothelial cells. Brain Research. 920:125-133.

[62] Lidinsky WA, Drewes LR . (1983). Characterization of the bloodbrain barrier: Protein composition of the capillary endothelial cell membrane. Journal of Neurochemistry. 41:1341-1348.

[63] Lossinsky AS, Vorbrodt AW, Wisniewski HM. (1983). Ultracytochemical studies of vesicular and canalicular transport structures in the injured mammalian blood-brain barrier. Acta Neuropathologica. (Berl). 61:239-245.

[64] Male D. (1995). The blood-brain barrier - No barrier to a determined lymphocyte. In: Greenwood J, Begley DJ, Segal MB. (eds). New Concepts of a Blood-Brain Barrier. Plenum Press, New York, pp 311-314.

[65] Maness LM, Kastin AJ, Farrell CL, Banks WA. (1998). Fate of leptin after intracerebroventricular injection into the mouse brain. Endocrinology. 139:4556-4562.

[66] Marsh M. (1984). The entry of enveloped viruses into cells by endocytosis. Biochemistry Journal. 218:1-10.

[67] Masereeuw R, Jaehde U, Langemeijer MWE, De Boer AG, Breimer DD. (1994). In vivo and in vitro transport of zidovudine (AZT) across the blood-brain barrier and the effects of transport inhibitors. Pharmacological Research 11:324-330.

[68] Mayhan WG, Heistad DD. (1985). Permeability of blood-brain barrier to various sized molecules. American Journal of Physiology. 248:H712-H718.

[69] MCGuire TR, Trickler WJ, Hock L, Vrana A, Hoie EB, Miller DW . (2003). Release of prostaglandin E-2 in bovine brain endothelial cells after exposure to three unique forms of the antifungal drug amphotericin-B: role of COX-2 in amphotericin-B induced fever. Life Sciences. 72:2581-2590.

[70] Miller DW. (1999). Immunobiology of the blood-brain barrier. Journal of Neurovirology. 5:570-578.

[71] Mukhtar M, Harley S, Chen P, BouHamdan M, Patel C, Acheampong E, Pomerantz RJ . (2002). Primary isolated human brain microvascular endothelial cells express diverse HIV/SIV-associated chemokine coreceptors and DC-SIGN and L-SIGN. Virology. 297:78-88.

[72] Nakaoke R, Ryerse JS, Niwa M, Banks WA. (2005). Human immunodeficiency virus type 1 transport across the in vitro mouse brain endothelial cell monolayer. Experimental Neurology. 193:101-109.

[73] Nottet HS, Persidsky Y, Sasseville VG, Nukuna AN, Bock P, Zhai QH, Sharer LR, McComb RD, Swindells S, Soderland C, Gendelman HE. (1996). Mechanisms for the transendothelial migration of HIV-1-infected monocytes into brain. Journal of Immunology. 156:1284-1295.

[74] Oldendorf WH. (1974). Lipid solubility and drug penetration of the blood-brain barrier. Proceedings of the Society for Experimental Biology and Medicine. 147:813-816

[75] Pan W, Banks WA, Fasold MB, Bluth J, Kastin AJ. (1998). Transport of brain-derived neurotrophic factor across the blood-brain barrier. Neuropharmacology. 37:1553-1561. 
[76] Pan W, Banks WA, Kastin AJ. (1997). Permeability of the bloodbrain barrier and blood-spinal cord barriers to interferons. Journal of Neuroimmunology. 76:105-111.

[77] Pan W, Banks WA, Kastin AJ. (1998). Permeability of the bloodbrain barrier to neurotrophins. Brain Research. 788:87-94.

[78] Pan W, Cornelissen G, Halberg F, Kastin AJ. (2002). Selected contributions: Circadian rhythm of tumor necrosis factor-alpha uptake into mouse spinal cord. Journal of Applied Physiology. 92:1357-1362.

[79] Pan W, Kastin AJ. (2001). Changing the chemokine gradient: $\mathrm{CINC1}$ crosses the blood-brain barrier. Journal of Neuroimmunology. 115:64-70.

[80] Pan W, Kastin AJ. (2001). Increase in TNF alpha transport after $\mathrm{SCI}$ is specific for time, region, and type of lesion. Experimental Neurology. 170:357-363.

[81] Pan W, Kastin AJ, Maness LM, Brennan JM. (1999). Saturable entry of ciliary neurotrophic factor into the brain. Neuroscience Letters. 263:69-71.

[82] Pan W, Vallance K, Kastin AJ. (1999). TGF $\alpha$ and the blood-brain barrier: accumulation in cerebral vasculature. Experimental Neurology. 160:454-459.

[83] Parameswaran SV, Steffens AB, Hervey GR, de Ruiter L. (1977). Involvement of a humoral factor in regulation of body weight in parabiotic rats. American Journal of Physiology. 232:R150-R157.

[84] Persidsky Y, Stins M, Way D, Witte MH, Weinand M, Kim KS, Bock P, Gendelman HE, Fiala M . (1997). A model for monocyte migration through the blood-brain barrier during HIV-1 encephalitis. Journal of Immunology. 158:3499-3510.

[85] Persidsky Y, Zheng J, Miller D, Gendelman HE. (2000). Mononuclear phagocytes mediate blood-brain barrier compromise and neuronal injury during HIV-1-associated dementia. Journal of Leukocyte Biology. 68:413-422.

[86] Power C, Kong PA, Crawford TO, Wesselingh S, Glass JD, McArthur JC, Trapp BD. (1993). Cerebral white matter changes in acquired immunodeficiency syndrome dementia: alterations of the blood-brain barrier. Annals of Neurology. 34:339-350.

[87] Price TO, Ercal N, Nakaoke R, Banks WA. (2005). HIV-1 viral proteins gp120 and Tat induce oxidative stress in brain endothelial cells. Brain Research. 1045:57-63.

[88] Pu H, Tian J, Flora G, Lee YW, Nath A, Hennig B, Toborek M. (2003). HIV-1 Tat protein upregulates inflammatory mediators and induces monocyte invasion into the brain. Molecular and Cellular Neurosciences. 24:224-237.

[89] Reese TS, Karnovsky MJ. (1967). Fine structural localization of a blood-brain barrier to exogenous peroxidase. Journal of Cell Biology. 34:207-217.

[90] Reyes TM, Fabry Z, Coe CL. (1999). Brain endothelial cell production of a neuroprotective cytokine, interleukin- 6 , in response to noxious stimuli. Brain Research. 851:215-220

[91] Sakata A, Tamai I, Kawazu K, Deguchi Y, Ohnishi T, Saheki A, Tsuji A. (1994). In vivo evidence for ATP-dependent and pglycoprotein-mediated transport of cyclosporin A at the bloodbrain barrier. Biochemistry and Pharmacology. 48:1989-1992.

[92] Schinkel AH, Wagenaar E, Mol CAAM, van Deemter L. (1996). PGlycoprotein in the blood-brain barrier of mice influences the brain penetration and pharmacological activity of many drugs. Journal of Clinical Investigation. 97:2517-2524.

[93] Schweighardt B, Atwood WJ. (2001). Virus receptors in the human central nervous system. Journal of Neurovirology 7:187-195.

[94] Shimura T, Tabata S, Ohnishi T, Terasaki T, Tsuji A. (1991). Transport mechanism of a new behaviorally highly potent adrenocorticotropic hormone . (ACTH). analog, ebiratide, through the blood-brain barrier. Journal of Pharmacology and Experimental Therapeutics. 258:459-465

[95] Slimani H, Charnaux N, Mbemba E, Saffar L, Vassy R, Vita C, Gattegno L. (2003). Binding of the CC-chemokine RANTES to syndecan-1 and syndecan-4 expressed on HeLa cells. Glycobiology. 13:623-634.

[96] Takasawa M, Terasaki T, Suzuki H, Sugiyama Y. (1997). In vivo evidence for carrier-mediated efflux transport of 3'azido3'deoxythymidine and 2',3'-dideoxyinosine across the blood-brain barrier via a probenecid-sensitive transport system. Journal of Pharmacology and Experimental Therapeutics. 281:369-375.
[97] Tayarani I, Chaudiere J, Lefauconnier JM, Bourre JM. (1987). Enzymatic protection against peroxidative damage in isolated brain capillaries. Journal of Neurochemistry. 48:1399-1402.

[98] Taylor EM. (2002). The impact of efflux transporters in the brain on the development of drugs for CNS disorders. Clinical Pharmacokinetics. 41:81-92.

[99] Terasaki T, Pardridge WM . (1988). Restricted transport of 3'azido-3'-deoxythymidine and 2'-3'-dideoxynucleosides through the blood-brain barrier. Journal of Infectious Diseases. 158:630-632.

[100] Terasaki T, Takakuwa S, Saheki A, Moritani S, Shimura T, Tabata S, Tsuji A. (1992). Absorptive-mediated endocytosis of an adrenocorticotropic hormone . (ACTH). analogue, ebiratide, into the blood-brain barrier: studies with monolayers of primary cultured bovine brain capillary endothelial cells. Pharmological Research. 9:529-534

[101] Thomas SA. (2004). Anti-HIV drug distribution to the central nervous system. Current Pharmaceutical Design. 10:1313-1324.

[102] Toborek M, Lee YW, Flora G, Pu H, Andreeff M, Wylegala E, Henning B, Nath A. (2005). Mechanisms of the blood-brain barrier disruption in HIV-1 infection. Cellular and Molecular Neurobiology. 25:181-199.

[103] Vadeboncoeur N, Segura M, Al-Numani D, Vanier G, Gottschalk M. (2003). Proinflammatory cytokine and chemokine release by human brain microvascular endothelial cells stimulated by Streptococcus suis serotype 2. FEMS Immunology and Medical Microbiology. 35:49-58.

[104] Villegas JC, Broadwell RD. (1993). Transcytosis of protein through the mammalian cerebral epithelium and endothelium: II Adsorptive transcytosis of WGA-HRP and the blood-brain and brain-blood barriers. Journal of Neurocytology. 22:67-80.

[105] Vorbrodt AW . (1994). Glycoconjugates and anionic sites in the blood-brain barrier. In: Nicolini M, Zatta PF . (eds). Glycobiology and the Brain. Pergamon Press, Oxford, pp 37-62.

[106] Vorbrodt AW, Dobrogowska DH, Ueno M, Lossinsky AS. (1995). Immunocytochemical studies of protamine-induced blood-brain barrier opening to endogenous albumin. Acta Neuropathologica. (Berl). 89:491-499.

[107] Wang Y, Sawchuck RJ. (1995). Zidovudine transport in the rabbit brain during intravenous and intracerebroventricular infusion. Journal of Pharmacological Sciences. 7:871-876

[108] Weber SJ, Abbruscato TJ, Brownson EA, Lipkowski AW, Polt R, Misicka A, Haaseth RC, Bartosz H, Hruby VJ, Davis TP. (1993). Assessment of an in vitro blood-brain barrier model using several [Met ${ }^{5}$ enkephalin opioid analogs. Journal of Pharmacology and Experimental Therapeutics. 266:1649-1655.

[109] Wolburg H, Wolburg-Buchholz K, Engelhardt B. (2005). Diapedesis of mononuclear cells across cerebral venules during experimental autoimmune encephalomyelitis leaves tight junctions intact Acta Neuropathologica. 109:181-190.

[110] Wu D, Clement JG, Pardridge WM . (1998). Low blood-brain barrier permeability to azidothymidine . (AZT)., 3TC, and thymidine in the rat. Brain Research. 791:313-316.

[111] Yamada S, DePasquale M, Patlak CS, Cserr HF. (1991). Albumin outflow into deep cervical lymph from different regions of rabbit brain. American Journal of Physiology. 261:H1 197-H1204.

[112] Yeagle P. (1987). Transport. The Membranes of Cells. Academic Press, Inc., Orlando, pp 191-215.

[113] Yu YG, King DS, Shin YK. (1994). Insertion of a coiled-coil peptide from influenza virus hemagglutinin into membranes. Science. 266:274-276.

[114] Zambenedetti P, Giordano R, Zatta P. (1996). Indentification of lectin binding sites in the rat brain. Glycoconjugate Journal. 13:341-346.

[115] Zidovetzki R, Wang JL, Chen P, Jeyasseelan R, Hofman F. (1998). Human immunodeficiency virus Tat protein induces interleukin 6 mRNA expression in human brain endothelial cells via protein kinase C- and cAMP-dependent protein kinase pathways. AIDS Research and Human Retroviruses. 14:825-833.

[116] Zlokovic BV, Yamada S, Holtzman D, Ghiso J, Frangione B. (2000). Clearance of amyloid beta-peptide from brain: transport or metabolism? Nature Medicine. 6:718-719. 